ORIGINAL ARTICLE

\title{
Breast cancer risk among Finnish cabin attendants: a nested case-control study
}

\author{
K Kojo, E Pukkala, A Auvinen
}

Occup Environ Med 2005;62:488-493. doi: 10.1136/oem.2004.014738

See end of article for authors' affiliations .....................

Correspondence to: Mrs K Kojo, School of Public Health, University of Tampere, FIN-33014

Tampere, Finland: katja.kojo@uta.fi

Accepted 18 March 2005

\begin{abstract}
Background: Earlier studies have found increased breast cancer risk among female cabin crew. This has been suggested to reflect lifestyle factors (for example, age at first birth), other confounding factors (for example, age at menarche), or occupational factors such as exposure to cosmic radiation and circadian rhythm alterations due to repeated jet lag.

Aims: To assess the contribution of occupational versus lifestyle and other factors to breast cancer risk among cabin attendants in Finland.

Methods: A standardised self-administered questionnaire on demographic, occupational, and lifestyle factors was given to 1041 cabin attendants. A total of 27 breast cancer cases and 517 non-cases completed the questionnaire. Breast cancer diagnoses were confirmed through the Finnish Cancer Registry. Exposure to cosmic radiation was estimated based on self-reported flight history and timetables. A conditional logistic regression model was used for analysis.

Results: In the univariate analysis, family history of breast cancer (OR=2.67, $95 \% \mathrm{Cl}: 1.00$ to 7.08 ) was the strongest determinant of breast cancer. Of occupational exposures, sleep rhythm disruptions $(O R=1.72,95 \% \mathrm{Cl}: 0.70$ to 4.27$)$ were positively related and disruption of menstrual cycles $(\mathrm{OR}=0.71$, $95 \% \mathrm{Cl}: 0.26$ to 1.96$)$ negatively related to breast cancer. However, both associations were statistically non-significant. Cumulative radiation dose $(\mathrm{OR}=0.99,95 \% \mathrm{Cl}$ : 0.83 to 1.19$)$ showed no effect on breast cancer.

Conclusions: Results suggest that breast cancer risk among Finnish cabin attendants is related to well established risk factors of breast cancer, such as family history of breast cancer. There was no clear evidence that the three occupational factors studied affected breast cancer risk among Finnish flight attendants.
\end{abstract}

$\mathrm{E}$ arlier studies of cancer incidence and cancer mortality among aircrew personnel have shown that overall cancer risk incidence and mortality are comparable with that in the general population. ${ }^{1}$ However, several studies have found increased breast cancer risk among female cabin crew. ${ }^{2-9}$ This has been suggested to reflect occupational exposure to cosmic radiation, hormonal alterations due to repeated jet lag, lifestyle factors, or confounding by factors such as age at menarche and menopause. The contribution of various factors has remained unclear, due to the fact that all earlier reports have limited extent of information on potential confounders-that is, the well known risk factors for breast cancer.

We conducted a nested case-control study of breast cancer among cabin attendants in Finland. The purpose of the study was to assess the contribution of occupational versus nonoccupational factors to breast cancer risk among cabin crew.

\section{METHODS}

\section{Data collection}

The source population consisted of all Finnish female airline cabin attendants, who were born in 1960 or before. A total of 1098 eligible woman were identified in the source population from the files of Finnair and Finnish Cabin Crew Union (table 1$)$.

In the source population, a total of 57 women (5\%) could not be traced because of death $(n=32)$, unknown current address $(n=17)$, or other reasons $(n=8)$. A standardised self-administered questionnaire (followed by two reminder letters for non-respondents) was mailed to all women with known addresses $(n=1041)$. Information was collected on: (1) demographic factors; (2) occupational factors including duration of active employment as cabin attendant, the monthly number of short, medium, and long haul flights, disturbances of sleep and menstrual cycle related to disruptions of circadian rhythm; and (3) other possible risk factors for breast cancer including number of births, age at first birth, breast feeding, number of spontaneous and induced abortions, age at menarche, age at menopause, use of oral contraceptives, participation in mammography screening, use of hormonal replacement therapy, family history of breast cancer, benign breast disease, alcohol consumption, and smoking habits.

Only those attendants who had ever worked as cabin attendants for Finnish flight companies for at least two years were included in the study. Short term employees were excluded as they have only negligible occupational exposure and may differ from the rest of the population in several respects, including breast cancer risk.

A total of 45 breast cancer cases were diagnosed in 19752000 among cabin attendants; 36 of those could be traced. The breast cancer cases were identified by a record linkage with the Finnish Cancer Registry, a nationwide, population based registry with a practically complete coverage of solid cancer cases in Finland. ${ }^{10}$

Radiation dose from occupational exposure to cosmic radiation was estimated based on reported flight history and Finnair timetables. Information on the average monthly number of flights by decade (1960s, 1970s, and 1980s) and flight category (domestic, Europe, Far East, North America, and other long haul) was collected using a self-administered

Abbreviations: $\mathrm{mSv}$, millisievert; $\mathrm{OR}$, odds ratio; $\mathrm{Cl}$, confidence interval; ERR, excess relative risk 
Main messages

- Finnish female cabin attendants have increased risk of breast cancer.

- Cabin attendants have the same risk factors for breast cancer as the general female population.

- There was no clear evidence that the three occupational factors studied affect breast cancer risk.

questionnaire. The questions concerning the flight history are shown in the Appendix. To complement the questionnaire data, we collected information on the frequency of flights from Finnair timetables and selected representative routes for each flight category. The radiation dose for every flight category was calculated using CARI-6 software, developed for this purpose by the US Federal Aviation Authority. ${ }^{11}$ Using the information on self-reported flight history and radiation dose by flight category, the cumulative occupational dose was calculated as the sum of radiation doses received in the 1960s through the 1980s. The dose received over the last 10 years prior the reference year was excluded to allow for the induction period of at least 10 years for radiation induced solid tumours. ${ }^{12}$ The occupational radiation dose assessment method has been described in detail elsewhere. ${ }^{13}$

All the study subjects gave written informed consent for participation. The Finnish Advisory Board for Radiation Safety approved the study protocol.

\section{Statistical analysis}

Information on all variables was taken into account before the reference year-that is, the year of breast cancer diagnosis for the cases and the date of diagnosis of the case for the controls.

The number of cumulative fertile years was calculated for postmenopausal women from age at menarche to the age at menopause, excluding periods of pregnancy and breast feeding. For premenopausal women, the number of cumulative fertile years was calculated from age at menarche to the reference year, excluding periods of pregnancy and breast feeding. The association between number of fertile years and breast cancer was analysed per five year increment in fertile years. Alcohol consumption was measured as a number of units $(0.33$ litres of beer or cider, $12 \mathrm{cl}$ wine, $8 \mathrm{cl}$ fortified wine, or $4 \mathrm{cl}$ spirits) per week. Alcohol consumption was categorised into two groups: 0-7 units per a week, and $>7$ units of alcohol consumed per a week. Family history of breast cancer was categorised into two groups: absence versus presence of breast cancer cases among first degree relatives (mother, sister, daughter). Miscarriages and abortions were merged as a one variable with two categories (no miscarriages or abortions and one or more miscarriages or abortions).

The association between breast cancer and cumulative radiation dose was analysed per $10 \mathrm{mSv}$ increment in dose, assuming a linear dose-response relation without a threshold. Active work years were defined as the time from beginning of cabin work to the end of work, less major absences from work, for example, maternity leaves or long sick leaves. Reported disturbances of sleep rhythm during long flights were categorised into two groups (never or rarely versus sometimes or often), as well as disturbances of menstrual cycle (never or rarely versus sometimes or often).

For each case, up to four controls were chosen with matching on year of birth $( \pm 1$ year). A conditional logistic regression model was used for both univariate and multivariate analysis with breast cancer status as the outcome
Policy implications

- There is no need to take occupational factors into account in breast cancer prevention among cabin attendants.

measure. Univariate analysis was done by including one independent variable of interest in the model. Multivariate analysis was used to study whether non-occupational factors affect the estimates obtained for occupational risk factors, and thus both occupational and non-occupational variables were included in the model. Non-occupational factors were selected on the basis of a priori criteria-that is, strong evidence on the relation to breast cancer risk. Confidence intervals reported are likelihood based. ${ }^{14}$

To assess possible selection bias (differences between participants and non-participants and their effect on the results), we calculated the odds ratio for breast cancer for all the subjects in the cabin attendant cohort (44 breast cancer cases and 921 non-cases, including those untraced subjects and non-participants whose start and end of cabin works was known) using crude exposure data available for every subject. Occupational dose was estimated based on number of active work years assessed from the dates of start and end of cabin work obtained from Finnair and the Finnish Cabin Crew Union. This information was combined with the estimated mean annual cosmic radiation dose by calendar period,,$^{13}$ to obtain a crude estimate of cosmic radiation dose for every person. The analyses were adjusted with age. Further, older women-that is, those who more likely have a longer recall period-might report flight activity, menstrual cycle distortions, and sleeping distortions with a different degree of accuracy than younger women. Thus, we assessed the modifying effect of age by dividing the study subjects into two groups ( 50 years of age or younger, and over 50 years of age) and examined the effect of occupational dose, sleep disturbances, and menstrual disturbances on breast cancer by age group.

\section{RESULTS}

A total of 544 flight attendants (27 cases and 517 non-cases) returned a completed questionnaire, corresponding to a response proportion of $60 \%$ for cases and $52 \%$ for non-cases. For each case, up to four controls were chosen; 27 cases and 103 controls were therefore included in the final analysis. Response proportions were similar for subjects living abroad

Table 1 Number of study participant cabin attendants by age group, date of hire, and case status

\begin{tabular}{lcll}
\hline & $\begin{array}{l}\text { Cases } \\
\mathbf{n}=27(45)\end{array}$ & $\begin{array}{l}\text { Controls } \\
\mathbf{n}=103(1053)\end{array}$ & $\begin{array}{l}\text { Total } \\
\mathbf{n}=130(1098)\end{array}$ \\
\hline Age group & & & \\
38 to 45 & $5(12)$ & $20(187)$ & $25(199)$ \\
46 to 55 & $16(20)$ & $66(320)$ & $82(340)$ \\
56 to 65 & $5(10)$ & $16(151)$ & $21(161)$ \\
66 to 81 & $1(2)$ & $1(49)$ & $2(51)$ \\
Date of hire & & & \\
$1950 \mathrm{~s}$ & $5(15)$ & $16(68)$ & $21(83)$ \\
$1960 \mathrm{~s}$ & $10(13)$ & $43(196)$ & $53(209)$ \\
$1970 \mathrm{~s}$ & $11(15)$ & $38(437)$ & $49(452)$ \\
$1980 \mathrm{~s}$ & $1(1)$ & $5(214)$ & $6(215)$ \\
$1990 \mathrm{~s}$ & $0(0)$ & $0(6)$ & $0(6)$ \\
\hline
\end{tabular}

The number of cabin attendants in the whole source population are given in parentheses. Totals differ in some cases because of missing data on specific characteristics. 
and those living in Finland (51\% and 54\% respectively). Those still working as a cabin attendant (typically younger) had higher participation rates $(62 \%)$ than those who had already quit their work (typically older) (43\%).

In the univariate analysis, family history of breast cancer ( $\mathrm{OR}=2.67,95 \% \mathrm{CI}$ : 1.00 to 7.08 ) had a borderline significant association with breast cancer (table 2). Non-significantly increased odds ratios were observed for alcohol consumption ( $\mathrm{OR}=2.67,95 \% \mathrm{CI}: 0.96$ to 7.38 ), early menarche (age of 12 or earlier) ( $\mathrm{OR}=2.04,95 \% \mathrm{CI}: 0.79$ to 5.30 ), number of fertile years $(\mathrm{OR}=1.33,95 \% \mathrm{CI}: 0.70$ to 2.52$)$, breast feeding $(\mathrm{OR}=3.56,95 \% \mathrm{CI}: 0.40$ to 32.02$)$, benign breast disease $(\mathrm{OR}=1.67,95 \% \mathrm{CI}: 0.63$ to 4.43$)$, smoking $(\mathrm{OR}=1.82,95 \%$ CI: 0.78 to 4.23$)$, and disruption of sleep rhythm $(\mathrm{OR}=1.72$, 95\% CI: 0.70 to 4.27$)$. Disruption of menstrual cycles (OR $=0.71,95 \%$ CI: 0.26 to 1.96$)$ had a statistically nonsignificant protective effect on breast cancer, whereas cumulative radiation dose $(\mathrm{OR}=0.99,95 \% \mathrm{CI}: 0.83$ to 1.19$)$ showed no effect on breast cancer.

There was no substantial change in the occupational estimates when non-occupational factors were included into the model in the multivariate analysis. Family history of breast cancer (OR $=5.52,95 \% \mathrm{CI}$ : 1.44 to 21.23 ) and alcohol consumption ( $\mathrm{OR}=4.11,95 \% \mathrm{CI} 1.01$ to 16.72$)$ had the strongest association with breast cancer in multivariate analysis (table 2). Also, number of fertile years $(\mathrm{OR}=1.51$, $95 \%$ CI: 0.54 to 4.19 ) and sleep rhythm disruptions $(\mathrm{OR}=1.52,95 \% \mathrm{CI}: 0.49$ to 4.74$)$ were positively related to breast cancer, but the confidence intervals were wide. Disruption of menstrual cycles $(\mathrm{OR}=0.56,95 \% \mathrm{CI}$ : 0.12 to 2.61) had a statistically non-significant protective effect on breast cancer, whereas parity $(\mathrm{OR}=1.10,95 \% \mathrm{CI}: 0.23$ to $4.85)$ and cumulative radiation dose (OR $=0.93,95 \%$ CI: 0.68 to 1.27) showed negligible effects on breast cancer.

When the odds ratio (age adjusted) for breast cancer for all the subjects in the cabin attendant cohort was calculated using crude cosmic radiation exposure data, the occupational radiation dose was not associated with breast cancer ( $\mathrm{OR}=0.96$, 95\% CI: 0.83 to 1.11 ).

When the effect of occupational dose, sleep disturbances, and menstrual disturbances was assessed by age group, the mean cumulative occupational dose for women 50 years of age or younger was $27.2 \mathrm{mSv}$ (range $0-103.5 \mathrm{mSv}, 95 \% \mathrm{CI}$ : 20.9 to $33.4 \mathrm{mSv}$ ), and for women over 50 years of age,
$34.8 \mathrm{mSv}$ (range 0-136.8 mSv, 95\% CI: 26.9 to 42.7). For women 50 years of age or younger, the occupational dose was not associated with breast cancer ( $\mathrm{OR}=0.86,95 \% \mathrm{CI}$ : 0.52 to 1.42 ) and the result was similar among older women ( $\mathrm{OR}=$ 1.02, 95\% CI: 0.84 to 1.24). Among women 50 years age or younger, $58 \%$ reported having sleep disturbances sometimes or often; the percentage was $51 \%$ among women over 50 years of age. The association of sleep disturbances with breast cancer risk was negative among younger women $(\mathrm{OR}=0.70$, 95\% CI: 0.19 to 2.58 ) and positive among older women ( $\mathrm{OR}=3.62,95 \% \mathrm{CI}: 0.93$ to 14.08$)$. Thirty per cent of women 50 years age or younger reported having menstrual disturbances sometimes or often; the percentage was $27 \%$ among women over 50 years of age. The association of menstrual disturbances with breast cancer risk was negligibly protective, both in younger women $(\mathrm{OR}=0.89,95 \% \mathrm{CI}$ : 0.19 to 4.12$)$ and in older women $(\mathrm{OR}=0.52,95 \% \mathrm{CI}: 0.13$ to 2.04).

\section{DISCUSSION}

An earlier study ${ }^{2}$ showed a significant excess in the incidence of breast cancer (SIR 1.87) among Finnish cabin attendants. Based on updated follow up, the age adjusted breast cancer incidence is $81.2 / 100000$. In comparison, the breast cancer rate for general Finnish female population is approximately 57.4/100 000 (adjusted with the age distribution of cabin attendants). This result implies that the excess risk in the incidence of breast cancer among Finnish cabin attendants has persisted.

In our study family history of breast cancer was the strongest determinant of breast cancer. Earlier studies have also suggested family history as one of the strongest risk factors for breast cancer, especially in early onset disease. ${ }^{15}$ Yet, in a retrospective study recall bias may also occur-that is, people with a disease are more likely to be aware of a similar diagnosis in a relative. ${ }^{16}$ This leads to higher sensitivity in exposure assessment among cases and differential misclassification with overestimation of the effect. However, an evaluation on precision of reported family history of breast cancer in Finland suggested that selfreported family history is quite accurate. ${ }^{17}$ Alcohol consumption seemed to be associated with breast cancer. Even if the well established risk factors for breast cancer are hormone related, there is strong previous evidence of the effect of

Table 2 Odds ratios and 95\% confidence intervals from conditional logistic regression of breast cancer risk; results from univariate and multivariate analysis

\begin{tabular}{|c|c|c|}
\hline \multirow[b]{2}{*}{ Risk factor } & \multicolumn{2}{|l|}{ OR $(95 \% \mathrm{Cl})$} \\
\hline & Crude & Adjusted* $^{*}$ \\
\hline Cumulative radiation dose (per $10 \mathrm{mSv}$ ) & $0.99(0.83$ to 1.19$)$ & 0.93 (0.68 to 1.27$)$ \\
\hline Number of fertile years (per 5 years) & 1.33 (0.70 to 2.52$)$ & $1.51(0.54$ to 4.19$)$ \\
\hline \multicolumn{3}{|l|}{ Parity } \\
\hline No children & 1.00 & 1.00 \\
\hline 1 child or more & $0.64(0.23$ to 1.79$)$ & $1.10(0.23$ to 4.85$)$ \\
\hline \multicolumn{3}{|l|}{ Family history of breast cancer } \\
\hline Nó & 1.00 & 1.00 \\
\hline Yes & $2.67(1.00$ to 7.08$)$ & 5.52 (1.44 to 21.23$)$ \\
\hline \multicolumn{3}{|l|}{ Alcohol consumption } \\
\hline $0-7$ units per a week & 1.00 & 1.00 \\
\hline 7.1-28 units per a week & $2.67(0.96$ to 7.38$)$ & 4.11 (1.01 to 16.72$)$ \\
\hline \multicolumn{3}{|l|}{ Disruption of sleep rhythm } \\
\hline Never or rarely & 1.00 & 1.00 \\
\hline Sometimes or often & $1.72(0.70$ to 4.27$)$ & 1.52 (0.49 to 4.74$)$ \\
\hline \multicolumn{3}{|l|}{ Disruption of menstrual cycle } \\
\hline Never or rarely & 1.00 & 1.00 \\
\hline Sometimes or offen & $0.71(0.26$ to 1.96$)$ & $0.56(0.12$ to 2.61$)$ \\
\hline
\end{tabular}


alcohol consumption, even moderate, on breast cancer risk. ${ }^{18}{ }^{19}$ Differential recall bias might also occur with respect to alcohol consumption-that is, people with the disease are prone to exaggerate the exposures they think are related to the disease.

Furthermore, the number of fertile years-that is, the cumulative number of ovulatory cycles-had a minor positive relation to breast cancer. There is previous evidence that the cumulative number of ovulatory cycles (that is, cumulative oestrogen exposure due to early menarche, late menopause, etc) is a major determinant of breast cancer. ${ }^{15}$ However, the phenomenon is difficult to study since many other exposures (age at menarche, breast feeding, parity, etc) are strongly associated with number of fertile years. There is strong previous evidence for the protective effect of parity against breast cancer in general. ${ }^{15}$ In this study, protective association was found but the confidence intervals were wide. Among parous women, breast feeding increased the risk of breast cancer in univariate analysis. This is opposite to previous evidence for a minor protective effect of breast feeding from breast cancer. ${ }^{20}$

Disruptions in sleeping pattern or menstrual cycle during flights across several time zones have been suspected to increase breast cancer risk. ${ }^{21}$ This is believed to be due to excess exposure to light during normal sleeping hours and thus impaired pineal secretion of melatonin. ${ }^{22}$ The melatonin hypothesis is supported by epidemiological studies on blind people. Blind people have increased levels of melatonin and have approximately half the rate of breast cancer. ${ }^{23}{ }^{24}$ The relation is still not fully understood and needs further research. In this study, reported sleeping disorders seemed to increase the risk of breast cancer but the relation was not statistically significant.

Menstrual cycle disruptions are common in flight attendants. ${ }^{25}$ In our study, menstrual disruptions were negatively associated with breast cancer but the relation was not statistically significant. There is some previous evidence that short menstrual cycle might increase breast cancer risk. ${ }^{15}$ The nature of the menstrual cycle disruptions of the cabin attendants is not known.

Risk of breast cancer was not associated with the cumulative occupational radiation dose. The expected magnitude of risk was small and we could not exclude a minor effect. The highest credible value was estimated as the upper limit of $95 \%$ confidence interval (1.274) - that is, $27.4 \%$ per $10 \mathrm{mSv}$. The validity of cosmic radiation exposure assessment has been thoroughly evaluated. However, a validation study is not possible, since in the Finnish setting the cabin attendants themselves are the only source of information on flight hours. There is a possibility of recall bias given the long recall period. In a previous study, we compares doses calculated from the flight hours based on questionnaires (individual data) with those based on number of flights per flight attendant, extracted from flight timetables (aggregate data). ${ }^{13}$ The results suggest that cabin attendants may overestimate their flight hours. A similar phenomenon was observed in an American study, where it was found that cabin attendants considerably overestimate their block hours. ${ }^{26}$ Yet, it is difficult to assess the potential recall bias from these findings mainly pertaining to reliability (random error).

Among atomic bomb survivors, breast cancer is one of the cancers most strongly related to radiation dose $(E R R=1.68$ per Sv, $90 \%$ CI 1.31 to 2.10 ; that is, $E R R=0.0168$ per $10 \mathrm{mSv}){ }^{27}$ The effect is strongest for exposures at young age, but weaker for women exposed after menopause. Similar results have been obtained in other studies of high dose rate exposures such as chest fluoroscopy. ${ }^{28}$ Yet, few studies have evaluated the effect of protracted exposure, for example, at work. Radiological technologists in the United States did not have an increased breast cancer mortality overall, but those certified prior to 1950 had an excess risk, with SMR of 1.5. ${ }^{29}$ Similar results have been obtained in a cohort of Chinese medical $x$ ray workers. ${ }^{30}$ However, both of these studies were limited by the lack of radiation dose estimates.

The main limitation of the study was the small number of cases, which restricts the statistical power. However, as the source population included practically all Finnish flight attendants, this constraint could not be overcome. Some results were inconsistent with earlier studies, which might be partly attributable to chance. Another limitation was that information on exposure was collected retrospectively. The case ascertainment was retrospective and therefore eight cases ( $18 \%$ ) were deceased and one case $(2 \%)$ had no current address. They were, therefore, unavailable for the study. The loss is assumed to be greater among breast cancer cases due to excess mortality and, therefore differential misclassification of exposure is possible, which may bias the result either away or towards the null.

To study the selection bias (participants versus nonparticipants), we calculated the odds ratio for breast cancer for the whole cabin attendant cohort using crude exposure data. The results showed that the occupational radiation dose was not associated with breast cancer. This result is comparable with that obtained in the main analyses (with smaller number of subjects) and indicates that selection bias attributable to incomplete tracing and participation did not substantially affect our findings.

One more limitation of the study was the suboptimal response proportion. If the selection effect is dissimilar among cases compared with controls (that is, exposure distribution in participants differs either more or less between participants and non-participants), selection bias could occur. Younger attendants actually had higher participation rates than older attendants. We assessed the modifying effect of age by dividing the study subjects into two groups ( 50 years of age or younger, and over 50 years of age) and examined the effect of occupational exposures on breast cancer by age group. No clear effect modification of age on the risk of breast cancer related to occupational exposures was observed. As expected, older women have accrued higher occupational doses, but the relation between radiation dose and breast cancer risk is fairly similar in the two groups. Results pertaining to the effect of sleep or menstrual disturbances on breast cancer risk are more difficult to interpret, as the estimates do differ, especially when the effect of sleep problems was assessed. However, the estimates can still be regarded as comparable due to wide confidence intervals. This suggests that the lower participation among older attendants did not distort the results.

In conclusion, our results suggest that breast cancer risk among Finnish cabin attendants is related to general, well established risk factors of breast cancer, such as family history of breast cancer. Occupational factors do not seem to exert an influence on breast cancer risk, but the evidence remains inconclusive.

\section{ACKNOWLEDGEMENTS}

We thank the Finnish Cabin Crew Union and Finnair for providing essential contact information on past and current cabin attendants and their periods of employment.

\section{Authors' affiliations \\ K Kojo, STUK-Radiation and Nuclear Safety Authority, Helsinki, Finland E Pukkala, Finnish Cancer Registry, Institute for Statistical and Epidemiological Research, Helsinki, Finland \\ A Auvinen, Tampere School of Public Health, University of Tampere, Tampere, Finland}

Competing interests: none declared 


\section{APPENDIX}

Part of the questionnaire sent to cabin attendants (the questions concerning flight history). Original questionnaire was in Finnish.

1. In which year did you start your cabin work at the first time? Year 19

2. Are you still doing the same work?

- No I am not, the year I stopped was 19

- Yes I am

3. Which duties did you perform during your cabin work?

- Cabin attendant from year 19 to 19

- Service chef/Finn hostess from year 19

- Assistant purser from year 19 19 to 19

- Purser from year 19 to 19

4. Were you away from your work, for example because of maternity leaves, nursing leaves or absences from duty?

- No I was not

- Yes, from year 19

- from year 19 to 19 to 19 9 months) and

- from year 19 to 19 months) and

- from year 19 to 19 months) and

- from year 19 to 19 ( months) and

- from year 19 to 19 months) and months)

5. Did you do any part time cabin work at any time?

- No I did not

_ Yes I did,__ or or_ hours per week from year 19 to 19 _ total of __ months

- and $\ldots$ total of or $\%$ months

6. Have you done other work, with some cabin work or no cabin work at all?

- No, I was not absent from cabin work

- Yes. What work? 19 _ total of months and

- What work? from year 19 to 19 total of months

7. How many round-trip flights did you have to Far East during different periods? For example Bangkok from year 1976, Tokyo from year 1983 and Singapore from year 1985 with aircraft DC8S during 1976-1982, DC10 during 1979-1996 and MDll from year 1992.

- 1970s on the average flights per a month

- 1980s on the average flights per a month

8. How many round-trip flights did you have to North America during different periods? For example to New York, Florida, California and Canada with aircraft DC8S during 1969-1982, DC10 from year 1975 and MDll from year 1992.

- 1970s on the average flights per a month

- 1980s on the average flights per a month

9. How many round-trip flights did you have to other outside-European destinations during different periods? For example charter flights to Canary Islands from year 1969.

- 1970s on the average flights per a month

- 1980s on the average flights per a month
10. How many round-trip flights did you have to Europe during different periods?

_ 1960s on the average___flights per a month

_ 1970s on the average__flights per a month

_ 1980s on the average___flights per a month

11. How many round-trip flights did you have to domestic destinations during different periods?

- 1960 s on the average___flights per a month
- 1970 s on the average___ flights per a month
_ 1980 s on the average_flights per a month

\section{REFERENCES}

1 Blettner M, Groshe B, Zeeb H. Occupational cancer risk in pilots and flight attendants: current epidemiological knowledge. Radiation Environ Biophys 1998;37:75-80.

2 Pukkala E, Auvinen A, Wahlberg G. Incidence of cancer among Finnish airline cabin attendants, 1967-92. BMJ 1995;311:649-52.

3 Lynge E. Risk of breast cancer is also increased among Danish female cabin attendants. BMJ 1996;312:253.

4 Wartenberg D, Stapleton CP. Risk of breast cancer is also increased among retired US female airline cabin attendants. BMJ 1998;316:1902.

5 Wartenberg D, Stapleton CP. Risk of breast cancer among female airline cabin attendants. BMJ 1999;318:126.

6 Rafnsson V, Tulinius H, Jónasson JG, et al. Risk of breast cancer in flight attendants: population based study (Iceland). Cancer Causes Control 2001;12:95-101.

7 Haldorsen T, Reitan JB, Tveten U. Cancer incidence among Norwegian airline cabin attendants. Int J Epidemiol 2001:30:825-30.

8 Reynolds P, Cone J, Layefsky M, et al. Cancer incidence in California flight attendants (United States). Cancer Causes Control 2002;13:317-24.

9 Rafnsson V, Sulem P, Tulinius $\mathrm{H}$, et al. Breast cancer risk in airline cabin attendants: a nested case-control study in Iceland. Occup Environ Med 2003;60:807-9.

10 Teppo L, Pukkala E, Lehtonen M. Data quality and quality control of a population-based cancer registry. Experience in Finland. Acta Oncol 1994:33:365-9.

11 Friedberg W. A computer program for calculating flight radiation dose. The Fed Air Surg Med Bull 1999;99:9-11.

12 Committee on the Biological Effects of lonizing Radiation (BEIR V) National Research Council. Health effects of exposure to low levels of ionizing radiation: BEIR V report. Washington, DC: National Academy Press, 1990.

13 Kojo K, Aspholm R, Auvinen A. Occupational radiation dose estimation for Finnish aircraft cabin attendants. Scand J Work Environ Health 2004;30:157-63.

14 Breslow NE, Day NE. Statistical methods in cancer research, Vol. I. The analysis of case-control studies. Lyon: International Agency for Research on Cancer, 1980.

15 Henderson B, Pike M, Bernstein L, et al. Breast cancer. In: Schottenfeld D, Fraumeni J, eds. Cancer epidemiology and prevention. New York: Oxford University Press, 1996.

16 Elwood JM. Critical appraisal of epidemiological studies and clinical trials. Oxford: Oxford University Press, 1998.

17 Eerola H, Blomqvist C, Pukkala E, et al. Familial breast cancer in southern Finland: how prevalent are breast cancer families and can we trust the family history reported by patients? Eur J Cancer 2000;36: 1143-8.

18 Stein CJ, Colditz GA. Modifiable risk factors for cancer. Br J Cancer 2004;90:299-303.

19 Key TJ, Allen NE, Spencer EA, et al. Nutrition and breast cancer. Breast 2003;12:412-16.

20 Lipworth L, Bailey LR, Trichopoulos D. History of breast-feeding in relation to breast cancer risk: a review of the epidemiologic literature. J Natl Cancer Inst 2000:92:302-12.

21 Rohr UD, Herold J. Melatonin deficiencies in women. Maturitas 2002;41(suppl 1):85-104.

22 Reiter RJ. Melatonin: clinical relevance. Best Pract Res Clin Endocinol Metab 2003; 17:273-85.

23 Kliukiene J, Tynes T, Andersen A. Risk of breast cancer among Norwegian women with visual impairment. Br J Cancer 2001;84:397-99.

24 Verkasalo PK, Pukkala E, Stevens RG, et al. Inverse association between breast cancer incidence and degree of visual impairment in Finland. Br J Cancer 1999;80:1459-60.

25 Suvanto S, Härmä M, Ilmarinen J, et al. Effects of $10 \mathrm{~h}$ time zone changes on female flight attendants' circadian rhythms of body temperature, alertness and visual search. Ergonomics 1993:36:613-25.

26 Grajewski B, Atkins DJ, Whelan EA. Self-reported flight hours vs. company records for epidemiologic studies of flight attendants. Aviat Space Environ Med 2004;75:806-10. 
27 Land CE, Tokunaga M, Koyama K, et al. Incidence of female breast cancer among atomic bomb survivors, Hiroshima and Nagasaki, 1950-1990. Radiat Res 2003;160:707-17.

28 Boice JD Jr, Preston D, Davis FG, et al. Frequent chest X-ray fluoroscopy and breast cancer incidence among tuberculosis patients in Massachusetts. Radiat Res 1991; 125:214-22.
29 Mohan AK, Hauptmann M, Linet MS, et al. Breast cancer mortality among female radiologic technologists in the United States. I Natl Cancer Inst 2002;94:943-8.

30 Wang JX, Zhang LA, Li BX, et al. Cancer incidence and risk estimation among medical $x$-ray workers in China, 1950-1995. Health Phys 2002;82:455-66.

\section{$\mathrm{ECHO}$}

\section{Search continues for causes of lead toxicity in Nigeria}

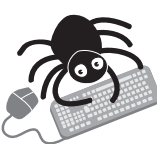

Please visit the Occupational and

Environmental Medicine website [www. occenvmed. com] for a link to the full text of this article. ombating lead toxicity in children in developing countries seems a distant prospect with the failure of a study to identify the main causes of exposure in urban Nigerian children with high lead concentrations in their bloodstream.

Multivariate analysis confirmed a link between a range of variables and high blood lead concentrations in two mostly Muslim administrative wards in Jos, Nigeria, one with a population with high amounts of lead in the bloodstream and one whose population had lower amounts. These were age $\leqslant 5$ years; male sex; chipped (lead based) paint in the home; a nearby outfit selling gasoline or a nearby battery smelter; cosmetic use of lead ore eye pencils in children; and, rather surprisingly, parental education. Together they accounted for just $38 \%$ of total variance. Living in the "high lead" ward remained significantly related to raised blood lead, suggesting a residual cause not already accounted for. Among adults and children with complete data from 34 households, 137 lived in the high lead (mean blood concentration 37 (SDl3) mg/l) and 138 in the low lead (mean 17 (10) mg/l) ward; 92 (34\%) had values $\geqslant 10 \mathrm{mg} / \mathrm{l}$.

Adults and children were questioned about sources of exposure, and lead in the blood was measured from blood spot samples taken from a washed finger.

Seventy per cent of children aged 6-35 months in Jos have raised blood lead concentrations. Lowering lead exposure is a key step in reducing its toxic effects on cognitive development, especially in children, combined with calcium, iron, and vitamin $\mathrm{C}$ supplements in developing countries.

A Wright NJ, et al. Archives of Disease in Childhood 2004;90:262-266. 